\title{
Inclusion of sorghum, millet and cottonseed meal in broiler diets: a meta-analysis of effects on performance
}

\author{
D. I. Batonon-Alavo ${ }^{1,2 \dagger}{ }^{\dagger}$, M. Umar Faruk ${ }^{2}$, P. Lescoat ${ }^{3}$, G. M. Weber ${ }^{4}$ and D. Bastianelli ${ }^{5}$ \\ ${ }^{1}$ INRA, UR83 Recherches Avicoles, F-37380 Nouzilly, France, ${ }^{2}$ Research Centre for Animal Nutrition and Health, DSM Nutritional Products France, F-68128 Village- \\ Neuf, France; ${ }^{3}$ AgroParisTech, UMR 1048 SADAPT, F-75005 Paris, France; ${ }^{4}$ DSM Nutritional Products Ltd, Nutrition Innovation Center, CH-4002 Basel, Switzerland; \\ ${ }^{5}$ CIRAD, UMR SELMET, Systèmes d'élevage méditerranéens et tropicaux, Baillarguet TA C-112/A, F-34398 Montpellier, France
}

\begin{abstract}
A meta-analysis was conducted (i) to evaluate broiler response to partial or total substitution of corn by sorghum and millet and (ii) to determine the effect of soybean meal replacement by cottonseed meal in broiler diet. The database included 190 treatments from 29 experiments published from 1990 to 2013. Bird responses to an experimental diet were calculated relative to the control (Experimental - Control), and were submitted to mixed-effect models. Results showed that diets containing millet led to similar performance as the corn-based ones for all parameters, whereas sorghum-based diets decreased growth performance. No major effect of the level of substitution was observed with millet or cottonseed meal. No effect of the level of substitution of sorghum on feed intake was found; however, growth performance decreased when the level of substitution of corn by sorghum increased. Cottonseed meal was substituted to soybean meal up to $40 \%$ and found to increase feed intake while reducing growth performance. Young birds were not more sensitive to these ingredients than older birds since there was no negative effect of these ingredients on performance in the starter phase. Results obtained for sorghum pointed out the necessity to find technological improvements that will increase the utilization of these feedstuffs in broiler diet. An additional work is scheduled to validate these statistical results in vivo and to evaluate the interactions induced with the simultaneous inclusions of sorghum, millet and cottonseed meal in broiler feeding.
\end{abstract}

Keywords: meta-analysis, broiler, sorghum, millet, cottonseed meal

\section{Implications}

As the demand in feed ingredients for poultry production is increasing, finding alternatives to corn and soybean meal utilization becomes a necessity. Conflicting results were reported in literature on the use of sorghum or millet to replace corn, and cottonseed meal as replacement to soybean meal. This study proposed quantitative knowledge of broiler response to dietary inclusion of sorghum, millet and cottonseed meal, which might lead to an increasing utilization of these feedstuffs.

\section{Introduction}

As a consequence of the consistent development of animal production, especially poultry production, there is an increasing demand for feed ingredients supplying energy and protein for poultry (Rae and Ngaya, 2010). Corn and wheat

\footnotetext{
${ }^{\dagger}$ E-mail: dolores.batonon@gmail.com
}

are the major cereal grains used with soybean meal in the least cost feed formulation for poultry (Rae and Ngaya, 2010; Ravindran, 2013a). The gap between local supply and demand for these major feed ingredients is expected to widen over the coming decades (Ravindran, 2013b). A strong increasing trend and a high variation of the prices of cereals grains and soybean meal have been observed in the last years. According to INSEE database, corn prices varied from $\$ 0.08$ per $\mathrm{kg}$ in January 2000 to $\$ 0.16$ per $\mathrm{kg}$ in December 2014 , whereas for soybean meal, it varied from $\$ 0.18$ per $\mathrm{kg}$ in January 2000 to $\$ 0.37$ per $\mathrm{kg}$ in December 2014 (INSEE, 2015). The prices volatility and changes in the availability of corn and soybean meal have spurred interest in using other feed ingredients produced in large scale (Ravindran, 2013b).

While sorghum (Sorghum bicolor) is the fifth major cereal produced in the world (Heuzé et al., 2012), millet (Pennisetum glaucum, Setaria italica) has been cultivated worldwide and used in animal nutrition (Heuzé and Tran, 2012). A protein-rich feed, cottonseed meal (Gossypium spp.) is a common feedstuff for animals, notably in cotton-producing 
areas such as India, China and United States (Heuzé et al., 2013). Several studies showed the interest of using sorghum or millet as alternatives to corn, and cottonseed meal in partial replacement of soybean meal. Utilization of millet in broiler feed resulted in similar (Davis et al., 2003; Hidalgo et al., 2004) or improved performance (Baurhoo et al., 2011) compared with corn-based diets, whereas conflicting results were reported for sorghum and cottonseed meal. Some studies showed a reduction in feed intake and weight gain in sorghum-based diets (Jacobs and Parsons, 2013), whereas others indicated similar performance as the control diet (Jacob et al., 1996). According to some studies (Azman and Yilmaz, 2005), cottonseed meal is a suitable replacement for soybean meal, observing that poultry performance was not different between the two ingredients. However, Watkins et al. (1993) reported an increased feed intake with cottonseed meal and a higher feed conversion ratio (FCR) compared with soybean meal-based diets.

Based on several studies, there is no consensus on the recommended level of substitution of these ingredients in broiler feeding. Fifty percent corn replacement with lowtannin sorghum was possible for broiler diets, whereas $100 \%$ corn substitution had negative effects on the intestinal mucosa and performance (Torres et al., 2013). However, broilers can be fed up to $100 \%$ low tannin sorghum-based diets with similar FCR as the control diet (Jacob et al., 1996). Proposed replacement of corn by millet ranged from $10 \%$ to 100\% (Hidalgo et al., 2004; Goodarzi Boroojeni et al., 2011). According to Baurhoo et al. (2011), substitution rates of millet greater than $50 \%$ significantly improved BW and FCR compared with a corn-based diet, whereas no difference was reported between $5 \%$ and $75 \%$ substitution for Davis et al. (2003) and Manwar and Mandal (2009). No detrimental effect on broiler performance was pointed out up to $20 \%$ soybean meal substitution by cottonseed meal in the diet (Azman and Yilmaz, 2005), whereas performance was sometimes decreased at much lower inclusion rate. Given all these contradictory results on the level of substitution effect, a dose-response impact of these feed ingredients inclusion should be therefore studied.

All the above information demonstrates that there is no clear response of the effects of the use of sorghum, millet and cottonseed meal in poultry diet. Because results from a single classical experiment are specific to conditions under which observations were made, they cannot be the basis for a large inference space (Sauvant et al., 2008). It is therefore useful to collect results from these studies and apply relevant statistical tools to allow drawing objective conclusions. Meta-analysis is a relevant statistical method to aggregate data from previous published research and to quantify knowledge (St-Pierre, 2001; Sauvant et al., 2008). Thus, the objectives of this work were (i) to determine whether the presence of sorghum, millet and cottonseed meal in broiler feeding will affect the performance and (ii) to investigate the quantitative effect of partial or total substitution of corn with sorghum and millet, and partial replacement of soybean meal with cottonseed meal on performance in broiler.

\section{Material and methods}

\section{Description of the database}

Peer-reviewed publications investigating utilization of sorghum, millet and cottonseed meal as partial or total replacement of corn and soybean meal in broiler feeding were selected from 1990 to 2013. The inclusion of these studies was based on three criteria: (i) experiments involving commercial broiler lines; (ii) experiments reporting at least two of these variables: average daily feed intake (ADFI), average daily gain (ADG) or FCR; (iii) experiments detailing ingredients lists and basic nutritional characteristics of experimental diets. Thus, a database containing 190 treatments was established from 17 papers representing 29 experiments. For each experiment, information describing animals (line, sex, number of birds per replicate, age, BW), experimental conditions (birds housing, diet composition) and measured parameters was recorded. In publications where several experiments were reported, each experiment was identified with a separate code. The complete list of references used for the meta-analysis is given in Supplementary material S1.

\section{Calculations}

Treatment average was considered as the experimental unit. Summary statistics of the data used in the study are presented in Table 1. It can be observed that all the control diets were mainly based on corn and soybean meal. Sorghum and millet were substituted to corn and cottonseed meal was used to replace soybean meal. It was observed that in the experiments contained in the database, the tested feed ingredients were included to substitute the control feedstuffs. However, to ensure similar nutrients supply, the experimental diets were formulated with changes made in other feed ingredients inclusion rates. For instance, in milletbased diets, the level of inclusion of soybean meal was reduced compared with the control diet, whereas in cottonseed meal diets, the level of oil in the diet was increased. Therefore, the levels of substitution of sorghum and millet to corn and cottonseed meal to soybean meal were re-calculated according to equation (1):

$$
\begin{aligned}
& \text { Level }(\%) \\
& =\frac{\text { Exp.ingredient }}{\text { Targeted ingredient }_{\text {Control }}+\text { Additional ingredient }_{\text {Control }}} \times 100,
\end{aligned}
$$

with Exp.ingredient being the inclusion rate of sorghum, millet or cottonseed meal in the experimental diet; Targeted ingredient $_{\text {control }}$ the level of inclusion in the control diet of corn or soybean meal; Additional ingredient control $_{\text {the level of }}$ inclusion in the control diet of the other feed ingredients modified in the experimental diets.

Information about the feed ingredient cultivar or variety used was rarely mentioned in the publications and not all nutrients contents were given in the publications. Therefore, to ensure consistency within the database, the nutritional values (metabolizable energy, CP and amino acid) of each treatment were estimated using NRC tables of feedstuffs 
Batonon-Alavo, Umar Faruk, Lescoat, Weber and Bastianelli

Table 1 Diets nutrients composition and average performance collected in sorghum, millet and cottonseed meal databases used for the meta-analysis (mean \pm s.e.)

\begin{tabular}{|c|c|c|c|c|c|c|}
\hline & \multicolumn{6}{|c|}{ Database } \\
\hline & \multicolumn{2}{|c|}{ Sorghum } & \multicolumn{2}{|c|}{ Millet } & \multicolumn{2}{|c|}{ Cottonseed meal } \\
\hline & Control & Exp. ${ }^{1}$ & Control & Exp. & Control & Exp. \\
\hline Number of publications & \multicolumn{2}{|c|}{8} & \multicolumn{2}{|c|}{5} & \multicolumn{2}{|c|}{4} \\
\hline Number of experiments & \multicolumn{2}{|c|}{12} & \multicolumn{2}{|c|}{10} & \multicolumn{2}{|c|}{7} \\
\hline $\begin{array}{l}\text { Starter phase } \\
\text { Ingredient (\%) }\end{array}$ & \multicolumn{2}{|c|}{$n=40$} & \multicolumn{2}{|c|}{$n=37$} & \multicolumn{2}{|c|}{$n=28$} \\
\hline Corn & $49.2 \pm 1.4$ & $29.2 \pm 1.1$ & $54.7 \pm 1.7$ & $30.8 \pm 2.4$ & $53.8 \pm 1.0$ & $47.5 \pm 0.3$ \\
\hline Soybean meal & $36.3 \pm 0.7$ & $35.4 \pm 0.6$ & $35.9 \pm 0.9$ & $31.6 \pm 0.8$ & $33.8 \pm 1.3$ & $17.9 \pm 0.8$ \\
\hline Oil & $4.7 \pm 0.2$ & $4.1 \pm 0.2$ & $2.5 \pm 0.3$ & $3.3 \pm 0.2$ & $5.0 \pm 0.0$ & $7.5 \pm 0.0$ \\
\hline Exp. feed ingredient & - & $39.2 \pm 3.2$ & - & $36.6 \pm 3.7$ & - & $19.6 \pm 0.7$ \\
\hline $\mathrm{ME}(\mathrm{MJ} / \mathrm{kg})^{2}$ & $12.78 \pm 0.03$ & $12.74 \pm 0.04$ & $12.56 \pm 0.12$ & $12.46 \pm 0.08$ & $13.38 \pm 0.02$ & $13.38 \pm 0.01$ \\
\hline $\mathrm{CP}(\%)^{2}$ & $23.1 \pm 0.2$ & $22.7 \pm 0.1$ & $21.9 \pm 0.4$ & $21.6 \pm 0.2$ & $22.3 \pm 0.3$ & $23.2 \pm 0.17$ \\
\hline \multicolumn{7}{|l|}{ Performance } \\
\hline Final BW (g) & $408 \pm 70$ & $458 \pm 56$ & $522 \pm 34$ & $503 \pm 18$ & $732 \pm 37$ & $756 \pm 12$ \\
\hline ADFI (g/bird per day) & $35.1 \pm 4.0$ & $39.2 \pm 3.2$ & $39.0 \pm 2.5$ & $39.0 \pm 1.6$ & $58.2 \pm 2.5$ & $60.3 \pm 1.1$ \\
\hline ADG (g/bird per day) & $22.6 \pm 3.2$ & $24.1 \pm 2.5$ & $27.4 \pm 1.2$ & $27.2 \pm 0.7$ & $38.2 \pm 2.7$ & $39.4 \pm 1.0$ \\
\hline FCR & $1.68 \pm 0.10$ & $1.73 \pm 0.08$ & $1.36 \pm 0.07$ & $1.33 \pm 0.05$ & $1.54 \pm 0.08$ & $1.54 \pm 0.02$ \\
\hline $\begin{array}{l}\text { Grower phase } \\
\quad \text { Ingredient (\%) }\end{array}$ & \multicolumn{2}{|c|}{$n=40$} & \multicolumn{2}{|c|}{$n=32$} & \multicolumn{2}{|c|}{$n=19$} \\
\hline Corn & $52.1 \pm 1.9$ & $19.4 \pm 3.1$ & $58.7 \pm 2.4$ & $34.8 \pm 3.2$ & $63.1 \pm 2.9$ & $57.5 \pm 2.6$ \\
\hline Soybean meal & $25.1 \pm 1.9$ & $28.5 \pm 1.0$ & $31.0 \pm 1.8$ & $28.2 \pm 1.0$ & $22.2 \pm 3.1$ & $15.2 \pm 2.3$ \\
\hline Oil & $3.3 \pm 0.8$ & $2.4 \pm 0.3$ & $2.7 \pm 0.3$ & $3.6 \pm 0.2$ & - & - \\
\hline Exp. feed ingredient & - & $54.5 \pm 1.5$ & - & $36.2 \pm 4.1$ & & $21.3 \pm 2.9$ \\
\hline $\mathrm{ME}(\mathrm{MJ} / \mathrm{kg})^{2}$ & $14.4 \pm 0.4$ & $14.3 \pm 0.2$ & $12.83 \pm 0.17$ & $12.62 \pm 0.10$ & $13.40 \pm 0$ & $13.40 \pm 0$ \\
\hline $\mathrm{CP}(\%)^{2}$ & $20.0 \pm 0.3$ & $20.8 \pm 0.3$ & $20.0 \pm 0.6$ & $20.0 \pm 0.4$ & $20.2 \pm 1.1$ & $20.2 \pm 0.7$ \\
\hline \multicolumn{7}{|l|}{ Performance } \\
\hline Final BW (g) & $1952 \pm 275$ & $1700 \pm 161$ & $2026 \pm 164$ & $2007 \pm 106$ & $2663 \pm 109$ & $2492 \pm 83$ \\
\hline ADFI (g/bird per day) & $143 \pm 15$ & $115 \pm 10$ & $144 \pm 18$ & $135 \pm 9$ & $156 \pm 3$ & $155 \pm 3$ \\
\hline ADG (g/bird per day) & $52.8 \pm 6.6$ & $47.6 \pm 4.3$ & $69.5 \pm 5.3$ & $69.8 \pm 3.7$ & $75.0 \pm 1.8$ & $71.6 \pm 1.4$ \\
\hline FCR & $2.44 \pm 0.18$ & $2.36 \pm 0.11$ & $2.04 \pm 0.14$ & $1.95 \pm 0.08$ & $2.16 \pm 0.08$ & $2.17 \pm 0.06$ \\
\hline Reference $^{3}$ & \multicolumn{2}{|c|}{$\begin{array}{l}\text { Douglas et al. (1990), Nyachoti et al. } \\
\text { (1996), Jacob et al. (1996a,b), Ayssiwede } \\
\text { et al. (2009), Kwari et al. (2011), Jacobs } \\
\text { and Parsons (2013), Torres et al. (2013) }\end{array}$} & \multicolumn{2}{|c|}{$\begin{array}{l}\text { Davis et al. (2003), Hidalgo et al. } \\
\text { (2004), Manwar and Mandal (2009), } \\
\text { Baurhoo et al. (2011), Goodarzi } \\
\text { Boroojeni et al. (2011) }\end{array}$} & \multicolumn{2}{|c|}{$\begin{array}{l}\text { Gamboa et al. (2001), Henry et al. } \\
\text { (2001), Sterling et al. (2002), } \\
\text { Azman and Yilmaz (2005) }\end{array}$} \\
\hline
\end{tabular}

ME = metabolizable energy. Values indicated for diet composition are the average of the amount of ingredients (\%) included in experimental treatments. The sum of ingredients is therefore not necessarily $100 \%$.

${ }^{1}$ Exp.: Experimental.

${ }^{2} \mathrm{ME}$ and CP contents are the average reported values in the publications.

${ }^{3}$ The complete list of references used for the meta-analysis is given in Supplementary material S1.

composition (NRC, 1994). S. bicolor composition was chosen for treatments involving sorghum, whereas pearl millet ( $P$. glaucum) was retained for millet experiments. Nutritional composition of cottonseed meal-based diets was estimated using cottonseed meal (Gossypium spp.) prepressed solvent extracted, $44 \%$ protein (NRC, 1994). Calculated nutritional composition of the treatments in each experiment is illustrated Figure 1. Each point is a treatment average. Large nutritional changes have been observed between and within experiment. No relationship existed between ME and CP contents. For a similar ME content in cottonseed meal diets, different levels of $C P$ were observed. Lysine and methionine contents were positively related to protein level in the diet.
Production phases were coded according to experimental periods mentioned in the publications. Thus, starter phase covered data collected between 0 and 21 days of age, whereas the growing phase ranged from 21 to 42 days of age. In sorghum-based experiments, a study ranging from 29 to 57 days of age (Jacob et al., 1996) was included in the growing phase. Descriptive statistics showed ADFI, ADG, final $B W$ and FCR varied between each ingredient database (Table 1). Bird responses to an experimental diet were calculated relative to the control as absolute values (Experimental - Control) or as percentages ((Experimental-Control)/Control). These values were then reported as $\delta A D F I, \delta A D G, \delta M E$ intake and $\delta C P$ intake, for $A D F I, A D G, M E$ intake and CP intake, respectively. $\delta \mathrm{FCR}$ was calculated as absolute values 
Sorghum subset

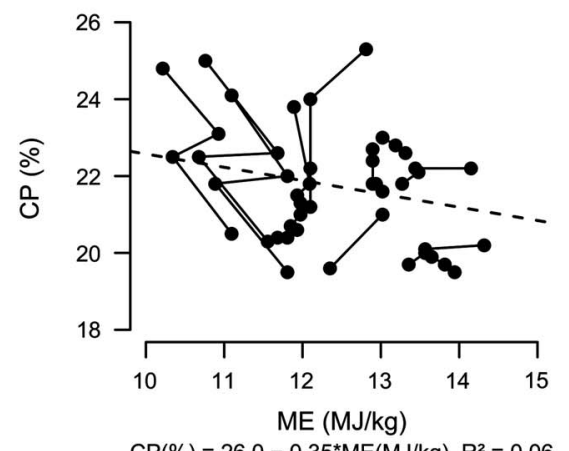

$\mathrm{CP}(\%)=26.0-0.35^{\star} \mathrm{ME}(\mathrm{MJ} / \mathrm{kg}), \mathrm{R}^{2}=0.06$

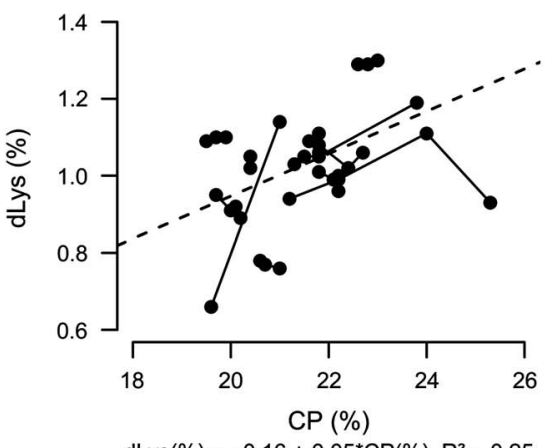

$\operatorname{dLys}(\%)=-0.16+0.05^{*} C P(\%), R^{2}=0.25$

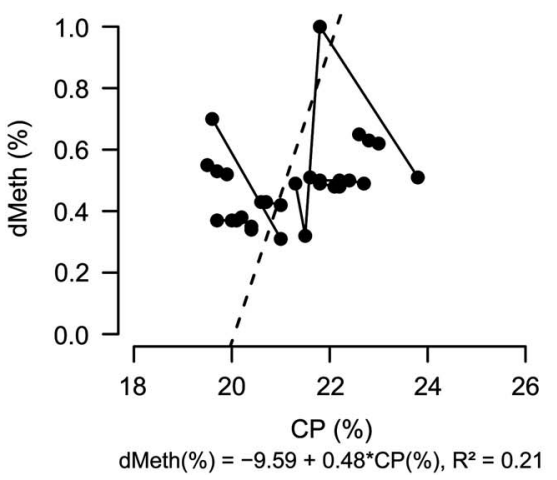

Millet subset

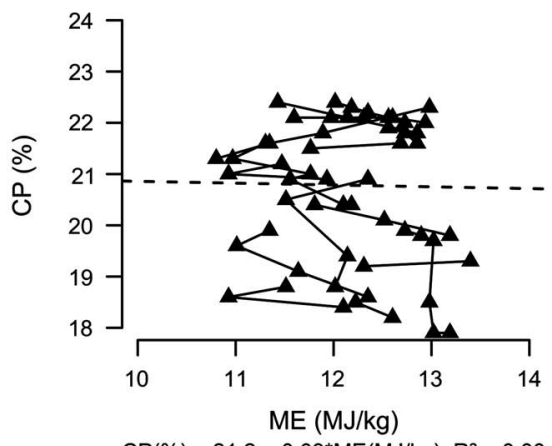

$C P(\%)=21.2-0.03^{*} \mathrm{ME}(\mathrm{MJ} / \mathrm{kg}), \mathrm{R}^{2}=0.00$
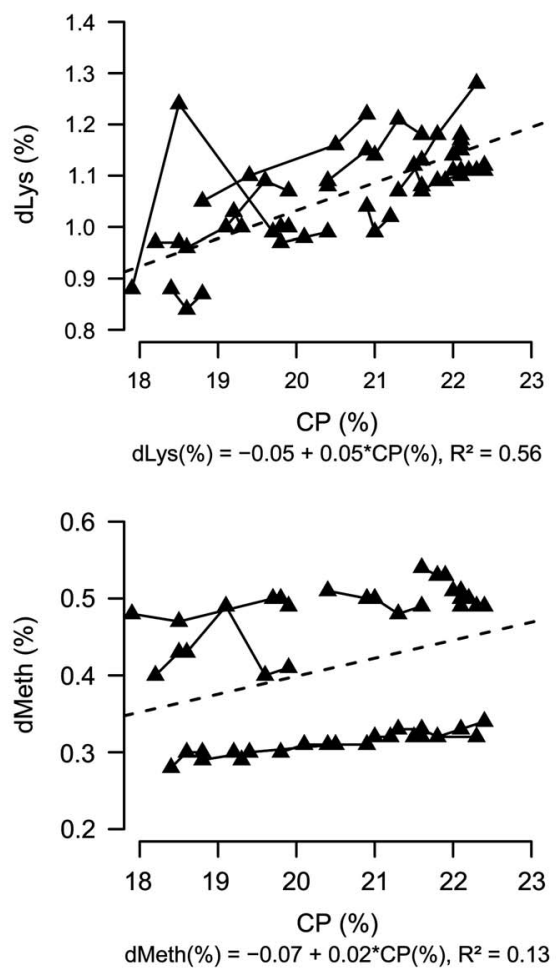

Cottonseed meal subset

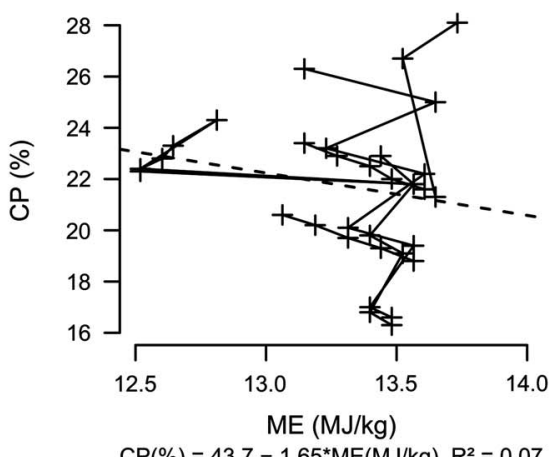

$\mathrm{CP}(\%)=43.7-1.65^{\star} \mathrm{ME}(\mathrm{MJ} / \mathrm{kg}), \mathrm{R}^{2}=0.07$
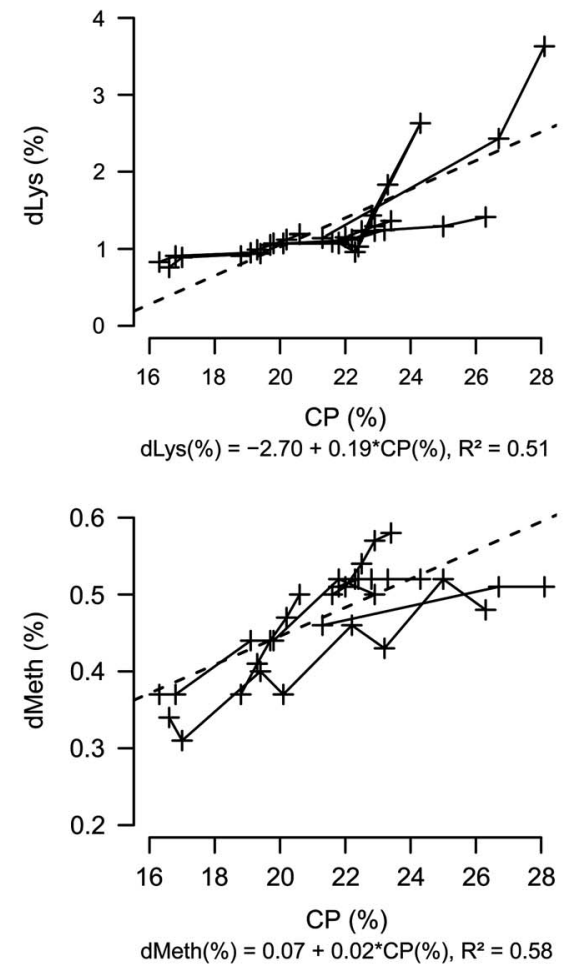

Figure 1 Relationship between the calculated metabolizable energy (ME) and CP contents and CP and amino acids contents of diets used in sorghum $(\mathbf{O})$, millet $(\boldsymbol{\Delta})$ and cottonseed meal $(+)$ experiments, respectively. Each point is a treatment average and observations are connected within each experiment. The dashed lines represent the linear adjustment between the two variables.

(Experimental - Control) for FCR. The advantage of using $\delta$ values is to take into account a large part of the variation existing between experiments.

\section{Statistical analysis}

Data analyses were performed using $\mathrm{R}$ version 3.0 .2 ( $\mathrm{R}$ Core Team, 2013). The whole database was separated in three subsets of data with sorghum, millet and cottonseed meal experiments, respectively. Global and within-study approaches were applied and discussed according to principles reported by St-Pierre (2001). Differences relative to control diet were submitted to one-way mixed effect model to determine whether the presence of sorghum, millet and cottonseed meal in the diets affected broiler response. $\delta \mathrm{ADFI}, \delta \mathrm{ME}$ intake, $\delta \mathrm{CP}$ intake, $\delta A D G$ and $\delta \mathrm{FCR}$ were then compared with the reference value $(\delta=0.00)$ of the control diet using equation (2) in each database. An experiment effect was included in the models as a random effect in order to take into account the sources of variation (bird line, environmental conditions and measurements methods) that may exist between experiments (Sauvant et al., 2008):

$$
y_{i j}=\alpha_{j}+x_{i j}+\varepsilon_{i j}
$$

where $y_{i j}$ is the measured variable $(\delta \mathrm{ADFl}, \delta \mathrm{ME}$ intake, $\delta \mathrm{CP}$ intake, $\delta \mathrm{ADG}$ and $\delta \mathrm{FCR})$ for treatment $i(i=$ control, sorghum-, millet- or cottonseed meal-based diets); $j$ the experiment number; $\alpha_{j}$ the random effect for experiment $j_{i} x_{i j}$ regimen effect and $\varepsilon_{i j}$ residual error. Results were considered significantly different if $P<0.05$ and tendencies were noted at $P$-values $\leqslant 0.10$.

Another aim of this study was to evaluate the effect of the level of substitution of each ingredient on broiler response. Thus, data of both starter and grower phases were combined 

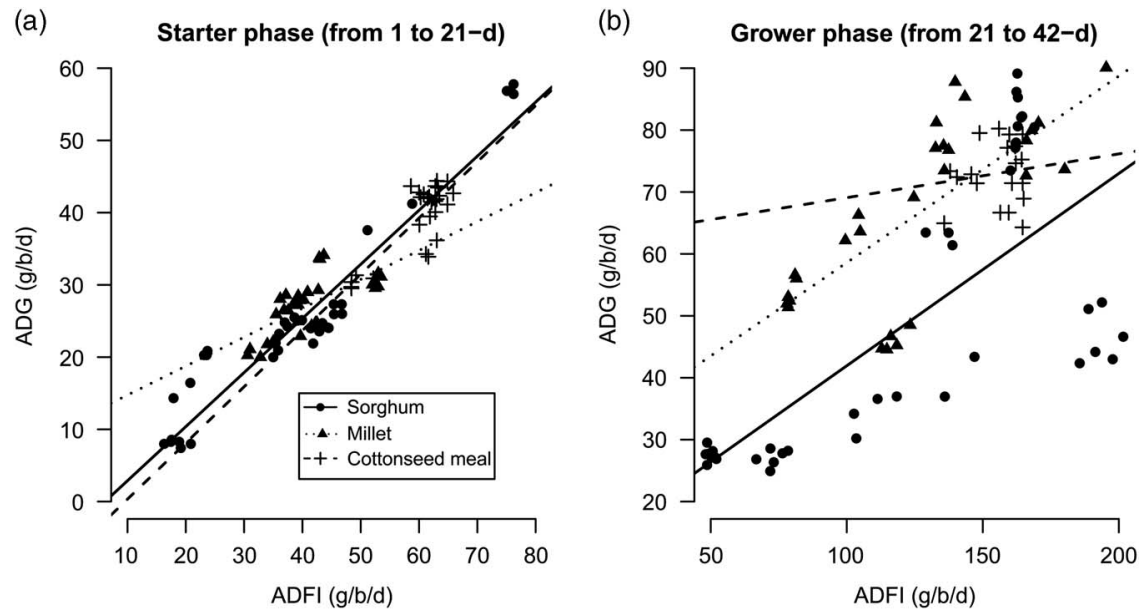

Figure 2 Average daily gain ( $g / b$ ird per day) as a function of average daily feed intake ( $g /$ bird per day) for sorghum, millet and cottonseed meal during starter (a) and grower (b) phases. The lines represent the linear regression between both variables. The overall adjustments for starter phase were: $\mathrm{ADG}=-4.60+0.75 \mathrm{ADFI}\left(R^{2}=0.91\right)$ for sorghum; $\mathrm{ADG}=10.75+0.40 \mathrm{ADFI}\left(R^{2}=0.48\right)$ for millet; $\mathrm{ADG}=-7.45+0.78 \mathrm{ADFI}\left(R^{2}=0.69\right)$ for cottonseed meal. Grower phase. Sorghum: $A D G=10.87+0.31 \mathrm{ADFI}\left(R^{2}=0.52\right)$; millet: $\mathrm{ADG}=28.46+0.30 \mathrm{ADFI}\left(R^{2}=0.64\right)$; cottonseed meal: $A D G=62.02+0.07 \mathrm{ADFI}\left(R^{2}=0.02\right)$. Where $A D G=$ average daily gain $(\mathrm{g} / \mathrm{bird}$ per day), $\mathrm{ADFI}=$ average daily feed intake (g/bird per day).

to assess this effect on the studied parameters. A two-way mixed effects model (equation (3)), including the production phase effect (starter $v$. grower) was performed on $\delta$ values expressed as percentage of the control diet for sorghum, millet and cottonseed meal as follows:

$$
y_{j k}=\mu+\alpha_{j}+\beta \text { Level }_{j k}+\text { Phase }_{j k}+\varepsilon_{j k}
$$

with $y_{j k}$ being the measured variable in the experiment $j$ at the production phase $k, \mu$ the overall intercept with fixed effect; $\alpha_{j}$ the random effect for experiment $j$ on the intercept $\mu ; \beta$, the coefficient of the level of substitution (Level); Phase the production phase effect and $\varepsilon_{j k}$ the residual error. Distributions of random effects $\left(\alpha_{j}\right)$ and residual error $\left(\varepsilon_{j k}\right)$ were assumed to be normal. The obtained models were evaluated using different criteria: the significance level of the estimated parameters, the coefficient of determination $\left(R^{2}\right)$ and the residual variation expressed as root mean square error (r.m.s.e.). The adequacy of the mixed models performed on the response to increasing level of substitution of each ingredient (equation (2)) was also assessed using residuals plots (Observed - Predicted) against predicted values of $Y$ to test for linear prediction bias (St-Pierre, 2001).

\section{Results}

\section{Data consistency}

Before any statistical analysis, ADG was expressed as function of ADFI in order to verify the consistency of the database (Figure 2). No clear outliers were denoted in both starter (from 1 to 21 days) and grower (from 21 to 42 days) phases. The results of the regression analysis allowed a conclusion of a relationship between $A D F I$ and $A D G$, with $A D F I$ explaining $84.3 \%$ of $A D G$ variance in starter phase and $54.0 \%$ in the grower one. However, for millet-based diets, a lower $R^{2}$ (0.25) was obtained during starter phase (not shown). This was related to one experiment with a much lower FCR $(0.85 \pm 0.04)$ compared with what could be expected according to guidelines (1.13). These data were eliminated from other analyses with a new $R^{2}$ of 0.48 . In the grower phase, sorghum data could suggest a quadratic model between ADG and ADFl; but the quadratic effect was found to be non-significant in the performed regression test.

Regressions analysis of nutritional composition showed a poor adjustment of calculated nutritional composition to reported composition (results not shown). For ME content in the starter phase, the slope and the intercept were significantly different from 0 , meaning that a slight relationship $\left(R^{2}=0.31\right)$ existed between recalculated and reported ME values. The opposite was observed for the grower phase for ME content with a low $R^{2}\left(R^{2}=0.08\right)$ and the slope significantly different from 0 . CP content was closer to reported data with $R^{2}=0.17$ and 0.56 , respectively, for starter and grower phases with a slope different from 0 in both cases. The reason of the differences between diets composition reported in the publications and our own calculations is probably the use of different feed tables, since the composition of ingredients was rarely analyzed by authors and reported in publications. Therefore, to ensure uniformity of information, the nutritional values used in the analyses were those calculated with NRC values (Figure 1).

\section{Effect of the inclusion of sorghum, millet and cottonseed meal on broiler performance}

Differences of performance relative to control diet were shown in terms of absolute values (Experimental - Control) and as percentages relatively to control (Experimental-Control)/ Control). No difference was observed in the statistical analyses for absolute values or percentages. Therefore, the results are discussed only as percentage of the control diet (Table 2).

Starter phase (from 1 to 21 days). Sorghum-based diets and cottonseed meal-based diets significantly increased ADFI 
Table 2 Responses relative to control diet for feed intake, nutrients intakes and growth performance to sorghum, millet and cottonseed meal utilization

\begin{tabular}{|c|c|c|c|c|c|c|c|c|c|c|c|c|}
\hline & \multicolumn{4}{|c|}{ Sorghum-based diets } & \multicolumn{4}{|c|}{ Millet-based diets } & \multicolumn{4}{|c|}{ Cottonseed meal-based diets } \\
\hline & $\begin{array}{c}\text { Mean } \pm \text { s.e. } \\
\text { (g/bird per day) }\end{array}$ & $P^{1}$ & $\begin{array}{l}\text { Mean } \pm \text { s.e. } \\
(\% \text { control })\end{array}$ & $P$ & $\begin{array}{c}\text { Mean } \pm \text { s.e. } \\
\text { (g/bird per day) }\end{array}$ & $P$ & $\begin{array}{l}\text { Mean } \pm \text { s.e. } \\
\text { (\% control) }\end{array}$ & $P$ & $\begin{array}{c}\text { Mean } \pm \text { s.e. } \\
\text { (g/bird per day) }\end{array}$ & $P$ & $\begin{array}{l}\text { Mean } \pm \text { se } \\
\text { (\% control) }\end{array}$ & $P$ \\
\hline \multicolumn{13}{|l|}{$\delta A D F I$} \\
\hline Starter phase & $1.23 \pm 0.44$ & ** & $3.80 \pm 1.21$ & $* * *$ & $-0.60 \pm 0.45$ & ns & $-1.75 \pm 1.33$ & ns & $1.95 \pm 0.38$ & * & $3.31 \pm 0.64$ & * \\
\hline Grower phase & $-6.41 \pm 2.54$ & $t$ & $-5.10 \pm 1.74$ & $t$ & $-11.37 \pm 3.84$ & $t$ & $-5.41 \pm 2.00$ & $\dagger$ & $3.75 \pm 1.43$ & * & $2.57 \pm 3.26$ & * \\
\hline \multicolumn{13}{|l|}{$\delta \mathrm{CP}$ intake } \\
\hline Starter phase & $0.23 \pm 0.08$ & ** & $3.29 \pm 0.97$ & $* * *$ & $-0.15 \pm 0.12$ & ns & $-1.96 \pm 1.50$ & ns & $1.49 \pm 0.21$ & $* * *$ & $11.60 \pm 1.57$ & $* * *$ \\
\hline Grower phase & $-1.86 \pm 0.58$ & ** & $-6.81 \pm 1.94$ & ** & $-2.20 \pm 0.86$ & ns & $-4.12 \pm 2.17$ & ns & $2.20 \pm 0.38$ & $* * *$ & $7.41 \pm 1.17$ & *** \\
\hline \multicolumn{13}{|l|}{$\delta A D G$} \\
\hline Starter phase & $-0.47 \pm 0.31$ & ns & $-1.51 \pm 1.33$ & ns & $0.12 \pm 0.24$ & ns & $0.43 \pm 0.89$ & ns & $-0.14 \pm 0.33$ & ns & $-0.12 \pm 0.83$ & ns \\
\hline Grower phase & $-2.31 \pm 0.62$ & ** & $-5.36 \pm 1.42$ & ** & $1.93 \pm 1.14$ & ns & $2.58 \pm 1.57$ & ns & $-2.96 \pm 0.38$ & * & $-3.95 \pm 1.17$ & * \\
\hline$\delta \mathrm{ME}$ intake & (MJ/bird per day) & & (\% control) & & (MJ/bird per day) & & (\% control) & & (MJ/bird per day) & & (\% control) & \\
\hline Starter phase & $0.02 \pm 0.00$ & $* * *$ & $4.19 \pm 1.04$ & $* * *$ & $-0.03 \pm 0.01$ & $* * *$ & $-7.09 \pm 1.61$ & ** & $-0.02 \pm 0.06$ & ns & $-2.29 \pm 0.73$ & ns \\
\hline Grower phase & $-0.03 \pm 0.03$ & ns & $-2.28 \pm 1.98$ & ns & $-0.24 \pm 0.06$ & * & $-10.57 \pm 2.15$ & ** & $0.01 \pm 0.02$ & ns & $0.64 \pm 0.90$ & ns \\
\hline \multicolumn{13}{|l|}{$\delta \mathrm{FCR}$} \\
\hline Starter phase & $0.09 \pm 0.02$ & $* * *$ & & & $-0.03 \pm 0.02$ & ns & & & $0.05 \pm 0.01$ & ns & & \\
\hline Grower phase & $0.01 \pm 0.03$ & ns & & & $-0.15 \pm 0.07$ & ns & & & $0.09 \pm 0.05$ & ns & & \\
\hline
\end{tabular}

ADFI = average daily feed intake; $\mathrm{ADG}$ = average daily gain; $\mathrm{FCR}$ = feed conversion ratio; $\mathrm{ME}$ = metabolizable energy.

$\delta A D F I$ and $\delta A D G$ are differences relative to control diets expressed in absolute values (Experimental - Control) or as percentages of the control ((Experimental - Control)/Control), respectively, in ADFI and ADG. $\delta F C R$ was expressed relative to the control in absolute value for FCR.

A $\quad P<0.001, * x<0.01 ; * P<0.05 ;+P \leqslant 0.10$. ns $=$ not significant at $P>0.10$.

A one-way mixed effect model was performed in each database to determine whether the presence of sorghum, millet and cottonseed meal in the diets affected broiler's response. $P$ is the probability of $\delta A D F I, \delta M E$ intake, $\delta C P$ intake, $\delta \mathrm{ADG}$ and $\delta \mathrm{FCR}$ to be different from the reference value $(\delta=0.00)$ of the control diet. 

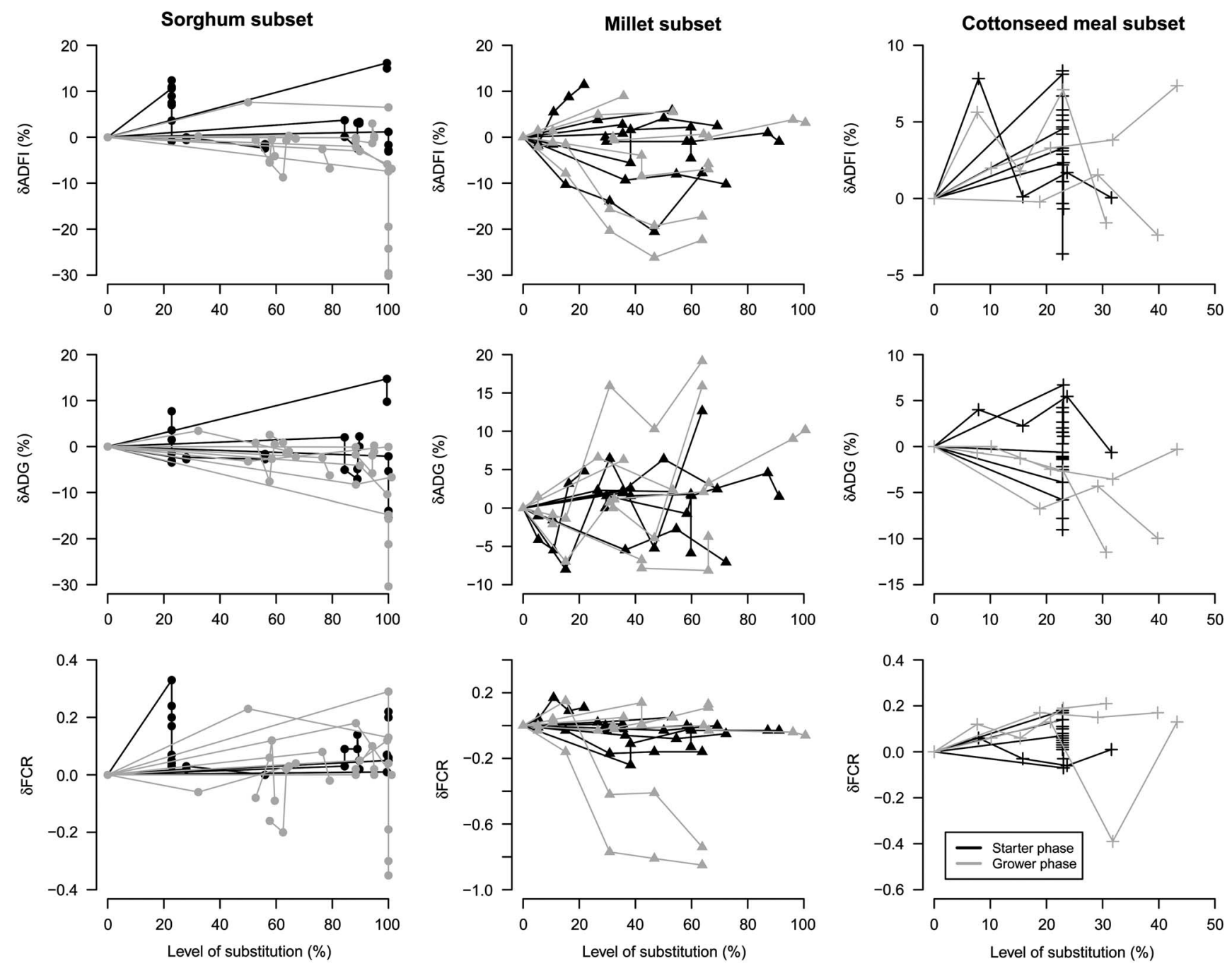

Figure $3 \mathrm{Global}$ and within-study responses of $\delta \mathrm{ADFI}, \delta \mathrm{ADG}$ and $\delta \mathrm{FCR}$ to an increasing level of substitution of sorghum $(\boldsymbol{\bullet})$, millet $(\boldsymbol{\Delta})$ and cottonseed meal $(+)$ for starter phase and grower phase. Observations belonging to one trial are connected with a solid line. ADFI = average daily feed intake; $A D G=$ average daily gain; $F C R=$ feed conversion ratio.

compared with the control diet with about $+3.80 \%$ and $+3.31 \%$, respectively. With millet-based diets, similar feed intake as the control diets was observed (Table 2). ME intake was, however, reduced $(-7.09 \%)$, whereas the opposite was observed with sorghum-based diets $(+4.19 \%)$. No difference of ME intake was observed between the control diets and cottonseed meal-based diets. An increase of CP intake was observed when birds were fed with sorghum-based diets and cottonseed meal-based diets in replacement of corn- or soybean meal-based diets, respectively. CP intake was similar among experimental treatments fed millet and those receiving the control diets. No effect of the feed ingredient was observed on growth rate since similar ADG were obtained between control and experimental diets with all three feed ingredients. Birds offered sorghum-based diets increased FCR by 0.09 compared with those fed corn-based diets. Average values obtained for $\delta \mathrm{FCR}$ showed no significant difference between control diet and millet-based diets or cottonseed meal-based diets.
Grower phase (from 21 to 42 days). During the grower phase, differences relative to the control diet in each experiment showed that millet-based diets tended to reduce ADFI $(P=0.10)$ but did not impact ADG (Table 2). ADG was found to be lower in sorghum-based diets $(-5.36 \%)$ compared with the control, whereas a trend was observed for ADFI $(P=0.05)$. Birds fed cottonseed meal-based diets increased ADFI by $2.57 \%$ while reducing ADG by $3.95 \%$ compared with the control. No significant effect of cottonseed meal and sorghum was found on ME intake contrary to millet, which decreased ME intake (-10.57\%). CP intake was not affected by millet, but it was affected by sorghum $(-6.81 \%)$ and cottonseed meal $(+7.41 \%)$. None of the tested ingredients significantly affected FCR during this phase.

\section{Broiler response to an increasing level of substitution} Observed $\delta A D F I, \delta A D G$ and $\delta F C R$ v. level of substitution are presented in Figure 3. No linear inter-study effect seems to exist between the level of substitution and any of the 
Table 3 Parameter estimates obtained from the mixed effects models (equation(2)) describing the responses in $\delta A D F I, \delta A D G$ and $\delta F C R$ as a function of level of substitution and the production phase for sorghum-, millet- and cottonseed meal-based diets

\begin{tabular}{|c|c|c|c|c|c|c|c|c|c|}
\hline & \multicolumn{3}{|c|}{ Sorghum-based diets } & \multicolumn{3}{|c|}{ Millet-based diets } & \multicolumn{3}{|c|}{ Cottonseed meal-based diets } \\
\hline & Coefficient & s.e. & $P^{1}$ & Coefficient & s.e. & $P$ & Coefficient & s.e. & $P$ \\
\hline \multicolumn{10}{|l|}{$\delta$ ADFI $(\% \text { control })^{2}$} \\
\hline Intercept & 1.20 & 2.08 & ns & -0.09 & 2.35 & ns & 0.60 & 0.91 & ns \\
\hline Level effect & -0.06 & 0.03 & ns & -0.08 & 0.04 & * & 0.06 & 0.04 & * \\
\hline Phase effect & & & ns & & & ns & & & ns \\
\hline Level $\times$ phase & & & $* *$ & & & ns & & & ns \\
\hline$R^{2}$ & \multicolumn{3}{|c|}{0.08} & \multicolumn{3}{|c|}{0.03} & \multicolumn{3}{|c|}{0.11} \\
\hline $\begin{array}{l}\text { r.m.s.e. } \\
\delta A D G(\% \text { control) })^{2}\end{array}$ & \multicolumn{3}{|c|}{5.66} & \multicolumn{3}{|c|}{6.11} & \multicolumn{3}{|c|}{2.73} \\
\hline Intercept & 1.36 & 1.74 & ns & -1.19 & 1.56 & ns & -0.06 & 1.05 & ns \\
\hline Level effect & -0.07 & 0.02 & $* * *$ & 0.09 & 0.03 & ** & -0.16 & 0.05 & * \\
\hline Phase effect & & & ns & & & ns & & & * \\
\hline Level $\times$ phase & & & * & & & ns & & & ns \\
\hline$R^{2}$ & \multicolumn{3}{|c|}{0.18} & \multicolumn{3}{|c|}{0.08} & \multicolumn{3}{|c|}{0.09} \\
\hline $\begin{array}{l}\text { r.m.s.e. } \\
\delta \mathrm{FCR}^{3}\end{array}$ & \multicolumn{3}{|c|}{4.74} & \multicolumn{3}{|c|}{4.83} & \multicolumn{3}{|c|}{3.15} \\
\hline Intercept & 0.00 & 0.03 & ns & 0.00 & 0.06 & ns & 0.02 & 0.03 & ns \\
\hline Level effect & 0.00 & 0.00 & ns & 0.00 & 0.00 & ns & 0.00 & 0.00 & $\dagger$ \\
\hline Phase effect & & & $\dagger$ & & & ns & & & ns \\
\hline Level $\times$ Phase & & & ns & & & ns & & & ns \\
\hline$R^{2}$ & \multicolumn{3}{|c|}{0.00} & \multicolumn{3}{|c|}{0.05} & \multicolumn{3}{|c|}{0.06} \\
\hline r.m.s.e. & \multicolumn{3}{|c|}{0.10} & \multicolumn{3}{|c|}{0.17} & \multicolumn{3}{|c|}{0.09} \\
\hline
\end{tabular}

r.m.s.e. $=$ root mean square error; $A D F I=$ average daily feed intake; $A D G=$ average daily gain; $F C R=$ feed conversion ratio.

$R^{2}$ : given for the relationship between the variable of interest and the level of substitution. .

$* * \star P<0.001 ;{ }^{* *} P<0.01 ;{ }^{*} P<0.05 ;+P \leqslant 0.10$. ns: not significant at $P>0.10$.

${ }^{1} A$ two-way mixed effect model including the production phase effect as co-variable and the experiment as random effect was performed on $\delta$ values from each database to determine the effect of the level of substitution on broiler's response.

${ }^{2} \delta A D F I, \delta A D G$ and are differences relative to control diets ((Experimental -Control)/Control), respectively, in ADFI, ADG and FCR.

${ }^{3} \delta \mathrm{FCR}$ was expressed relative to the control in absolute value (Experimental -Control) for FCR.

performance criteria studied. However, a substantial variation in the response could be observed across trials. Apparently, no difference seems to exist between starter and grower phase for all criteria.

Parameter estimates for equation (2) are reported in Table 3. In sorghum database, no significant effect of the level of substitution was observed on $\delta A D F I$ and $\delta F C R$. However, growth performance consistently decreased when the level of substitution of corn by sorghum increased. The regression analysis also showed that the only major relationship existed between the level of substitution of sorghum and the growth rate $\left(R^{2}=0.18\right)$. No difference was found for $\delta A D F I$ and $\delta A D G$ between the starter and the grower phase except for $\delta F C R$, which tended to be higher in the starter than in the grower phase $(P=0.06)$.

The level of substitution of corn by millet significantly impacted $\delta A D F I, \delta A D G$. A reduction of ADFI was observed with the increasing level of millet in broiler feeding, whereas the opposite was obtained for $\delta A D G$. However, the lower $R^{2}$ $\left(R^{2}=0.03\right.$ and $R^{2}=0.08$, respectively for $\delta \mathrm{ADFI}$ and $\delta A D G)$ indicated the lack of strong linear relationship between the level of substitution and these two criteria of performance. No influence of the level of substitution of millet on $\delta F C R$ was observed. These conclusions were similar in starter and grower phases since no effect of the production phase was observed on all the performance criteria studied. For cottonseed meal diets, a significant impact of the level of substitution was obtained on $\delta A D F I$ and $\delta A D G$ but it did not influence $\delta F C R$. $\delta A D G$ was affected by the production phase and found significantly higher in the grower phase. Lower values of r.m.s.e. (root mean square error) were observed for all criteria for sorghum, millet and cottonseed meal databases thus leading to a conclusion of a good accuracy of the fitted models.

\section{Model evaluation}

The residuals $v$. predicted values for all mixed models performed on the response to level of substitution are presented in Figure 4. No obvious patterns are evident in the plots. However, the slight deviation from the solid line (Observed = Predicted) observed in sorghum and millet indicated a small difference between observed and predicted values. Better predictions were obtained with cottonseed meal models, since both solid regressions and dashed lines cannot be distinguished. Despite some largest residuals observed in all ingredients, the lack of correlation $\left(R^{2} \approx 0\right)$ indicated a fairly good prediction of $\delta A D F I, \delta A D G$ and $\delta F C R$. Overall, all of the intercepts obtained from the regressions analysis were 

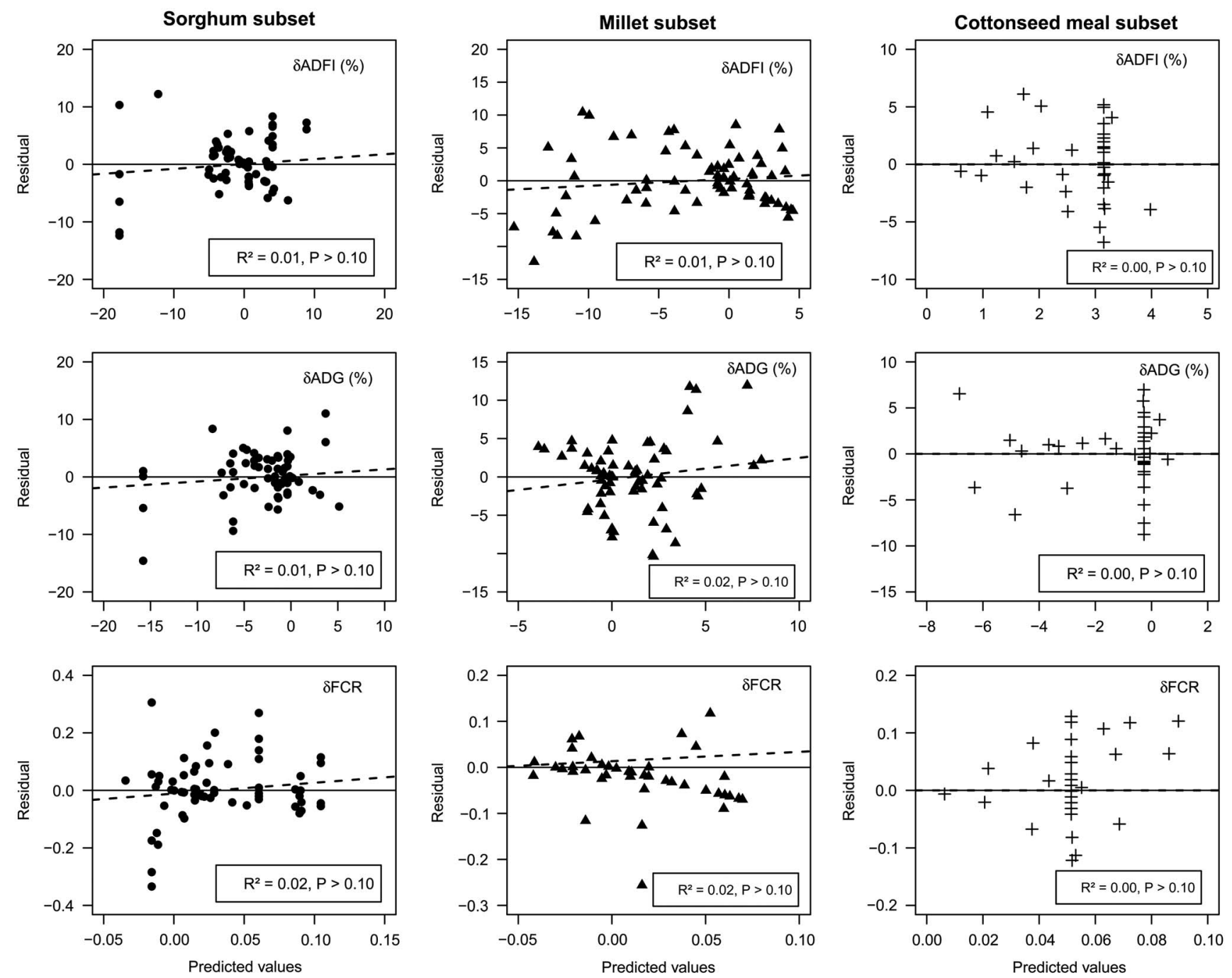

Figure 4 Plots of the Residual (Observed - Predicted) $v$. predicted values of the mixed effects models (equation (2)) for sorghum- $(\mathbf{O})$, millet- $(\mathbf{A})$ and cottonseed meal- $(+)$ based diets. Dashed lines represent the linear adjustment of residuals to predicted values.

significantly similar to $0(P>0.10)$ and the slope, almost null $(P>0.10)$, thus confirming the above mentioned results of the level of substitution on performance.

\section{Discussion}

The objective of the current study was to evaluate the effects of partial or total substitution of corn by sorghum and millet and the effect of soybean meal replacement by cottonseed meal on broiler performance. Results obtained indicated that millet can partially or totally replace corn in broiler feeding without any detrimental effect on performance and this is consistent with several authors (Davis et al., 2003; Hidalgo et al., 2004). No significant difference in feed intake and growth performance were observed with millet-based diets when compared with corn-based diets. However, numerical differences were observed with $A D F l$, which tended to be lower in millet-based diets. Despite the slight reductions of feed intake and ME intake, birds fed millet-based diets have similar growth performance to corn-based diets. This could be related to the well-balanced amino acid profile of pearl millet grains as well as the high essential amino acid concentrations and the high digestibility rate of these amino acids (Adeola and Orban, 1995; Yin et al., 2002).

Sorghum and cottonseed meal affected broiler performance in agreement with previous works (Watkins et al., 1993; Kwari et al., 2011). An increase in ADFI was obtained with cottonseed meal-based diets compared with control ones in both starter and grower phases. Since cottonseed meal-based diets were lower in calculated ME content $(\delta \mathrm{ME}=-0.73 \pm 0.07 \mathrm{MJ} / \mathrm{kg}$ and $\delta \mathrm{ME}=-0.25 \pm 0.05 \mathrm{MJ} /$ $\mathrm{kg}$, in starter and grower phases, respectively), birds adjust their consumption to satisfy energy requirements (PérezBonilla et al., 2012). Conversely, the reduction of ADFI observed with sorghum-based diets in the grower phase was associated with the higher energy level of these diets $(\delta \mathrm{ME}=+0.35 \pm 0.07 \mathrm{MJ} / \mathrm{kg})$ compared with the control diets $(P<0.05)$. During the starter phase, a higher consumption was observed with sorghum-based diets and was associated with the sorghum particle size in these 
experiments. Whole and coarse ground sorghum was offered to birds and found to increase feed intake in comparison with finer particles (Jacobs and Parsons, 2013). As reported by Nir et al. (1990), bird has a preference for larger particles and this preference increases with age.

Growth performance was reduced in sorghum- and cottonseed meal-based diets in the grower phase and this agreed with the reports of Ojewola et al. (2006) and Jacobs and Parsons (2013). This might be related to the content of anti-nutritional factors of both sorghum and cottonseed meal. Tannins and phytate in sorghum are known to form complexes with protein and carbohydrates, particularly with starch (Selle et al., 2010), thus leading to a reduction of nitrogen and starch digestibility (Mahmood et al., 2014). In addition, the effect of tannin on bird's performance depends on its dietary level and the amount of feed ingested. Birds fed high tannin diets suffered from a severe decrease of growth compared with low tannin or control fed birds (Mahmood et al., 2006). In cottonseed meal, free gossypol binds to lysine and reduces the lysine available for absorption (Henry et al., 2001). This component also inhibits the activity of pepsin and trypsin in gastro-intestinal tract, thereby reducing the digestibility of protein and growth in broilers (Nagalakshmi et al., 2007). Bird's tolerance to free gossypol depends on their age, protein content and quality, duration of feeding and presence of minerals especially the iron content in the diet (Nagalakshmi et al., 2007). According to Panigrahi and Morris (1991), significant improvements of feed intake and egg production were obtained when laying hens were given iron treated cottonseed meal-based diets. Therefore, increasing protein or amino acid in the diet was shown to overcome the deleterious effects of tannins and gossypol (Nagalakshmi et al., 2007). Since iron was not included in cottonseed meal-based diets of this meta-analysis, its utilization in broiler diet can be a way to improve the performance. Phytase supplementation can also be suggested to enhance amino acid digestibility in sorghum-based diets (Selle et al., 2010).

Overall, no significant differences were observed regarding the influence of millet-based diets and cottonseed meal-based on $\delta F C R$. Though, numerical reductions of FCR were obtained with millet-based diets in agreement with Baurhoo et al. (2011) and Goodarzi Boroojeni et al. (2011) and in line with the reduced feed intake observed in both starter and grower phases. A greater CP digestibility and the changes in the small intestine mucosa morphology were reported to be the factors leading to a better efficiency with millet utilization (Baurhoo et al., 2011; Goodarzi Boroojeni et al., 2011). On the contrary, feed efficiency was reduced with sorghum-based diets in starter phase accordingly with the higher consumption observed for equivalent growth performance as the corn-based diets.

Only a few differences ( $\delta A D G$ and $\delta \mathrm{FCR}$ ) were observed in starter phase compared with the grower phase for sorghumbased diets and cottonseed meal-based diets. There is no evidence of cumulative effect of gossypol or tannins in the literature; therefore, it can be hypothesized that the effect of sorghum and cottonseed meal observed in the grower phase is related to specific conditions (e.g. feed formulation) of the set of experiments selected in this production phase rather than a specific age-dependent effect. The lack of negative effect in starter phase does not justify restricting the use of these ingredients in younger birds.

The fitted models showed a very weak linear relationship between the level of substitution and the investigated criteria of performance. Although a significant effect of the level of substitution on $\delta A D F I$ and $\delta A D G$ was obtained with milletand cottonseed meal-based diets, low $R^{2}$ and slopes were determined. Based on these models, an average substitution of $33 \%$ of corn by millet, for example, would result in an increase of $A D G$ of $1.78 \%$, whereas soybean meal replacement by $17 \%$ of cottonseed meal would decrease growth performance by $2.78 \%$. It could then be hypothesized that no strong effect of the level of substitution was observed in millet-based diets and cottonseed meal-based diets, consistently with Davis et al. (2003) and Manwar and Mandal (2009). However, in sorghum-based diets, a negative correlation $\left(R^{2}=0.18\right)$ and high $P$-value were observed regarding the effect of the level of substitution of this feed ingredient on growth performance. This is in line with Kwari et al. (2011) and Torres et al. (2013) who demonstrated that higher substitution levels of corn by sorghum decreased growth performance. These results of performance might be explained by a dose-response effect of the anti-nutritional factors present in sorghum (phytate or tannins). Accumulation of phytate and tannins in the diet could dramatically depress protein digestion and thereby decrease protein synthesis for growth (Selle et al., 2010).

Variability in bird response to utilization of these feed ingredients was observed, suggesting that this is related to some unknown factors not considered in this analysis. Given that environmental conditions affected bird's response (Syafwan et al., 2012), information about temperature and relative humidity throughout the experiments could enhance the models' precision. In starter and grower phase, the intake of cottonseed meal-based diets increased with the level of substitution. At the same level of substitution, a wide variability was also observed and related to different experiments (Khalid et al., 2000) involving extruded cottonseed meal supplemented or not with amino acids. This variability in bird response could also be explained to the dietary level of anti-nutritional factors (Mahmood et al., 2006), since no such information was detailed in the selected publications. Furthermore, taking the experiment effect as a fixed effect in a GLM, as suggested by Sauvant et al. (2008) in case of heterogeneity between studies resulted in similar results like those obtained with the mixed effect models.

This meta-analytical approach provides significant quantitative knowledge to the utilization of these ingredients in both starter and grower phases. Cottonseed meal-based diets were given upon $40 \%$ of substitution and found to increase feed intake while reducing growth performance. Analyses showed that diets containing millet produced similar performance as the corn-based diets, whereas sorghum-based diets decreased growth performance. No major effect of the level of substitution was observed with millet and cottonseed meal; whereas with sorghum-based diets, a negative relationship was pointed out 
between the level of substitution of sorghum and growth performance. This study highlighted the necessity to find technological improvements that will lead to an increased utilization of these alternative feedstuffs, especially sorghum in poultry. However, in this investigation, information on environmental conditions throughout experiments, feedstuff varieties or antinutritional factors contents was not available and therefore these variables as such could not be included as factors in the analysis. This may be considered as a limiting factor to the present study. Thus, in order to evaluate the accuracy of the obtained models, two trials were conducted with sorghum, millet and cottonseed meal. The potential interactions that might be induced with the simultaneous inclusion of these ingredients on broiler performance and nutrients digestibility were also assessed. Results of these trials are presented in a separate paper.

\section{Acknowledgements}

The authors would like to acknowledge the support of DSM, INRA and CIRAD.

\section{Supplementary materials}

To view supplementary materials for this article, please visit http://dx.doi.org/10.1017/S1751731115000282

\section{References}

Adeola 0 and Orban J 1995. Chemical composition and nutrient digestibility of pearl millet (Pennisetum glaucum) fed to growing pigs. Journal of Cereal Science 22, 177-184.

Azman MA and Yilmaz M 2005. The growth performance of broiler chicks fed with diets containing cottonseed meal supplemented with lysine. Revue de Médecine Vétérinaire 156, 104-106.

Baurhoo N, Baurhoo B, Mustafa AF and Zhao X 2011. Comparison of corn-based and Canadian pearl millet-based diets on performance, digestibility, villus morphology, and digestive microbial populations in broiler chickens. Poultry Science 90, 579-586.

Davis AJ, Dale NM and Ferreira FJ 2003. Pearl millet as an alternative feed ingredient in broiler diets. Journal of Applied Poultry Research 12, 137-144.

Goodarzi Boroojeni F, Samie AH, Edriss MA, Khorvash M, Sadeghi G, Van Kessel A and Zentek J 2011. Replacement of corn in the diet of broiler chickens using foxtail millet produced by 2 different cultivation strategies. Poultry Science 90, 2817-2827.

Henry MH, Pesti GM, Bakalli R, Lee J, Toledo RT, Eitenmiller RR and Phillips RD 2001. The performance of broiler chicks fed diets containing extruded cottonseed meal supplemented with lysine. Poultry Science 80, 762-768.

Heuzé V and Tran G 2012. Pearl millet (Pennisetum glaucum) grain. Feedipedia. org. A programme by INRA, CIRAD, AFZ and FAO. Retrieved August 8, 2014, from http://www.feedipedia.org/node/724

Heuzé V, Tran G and Lebas F 2012. Sorghum grain. Feedipedia.org. A programme by INRA, CIRAD, AFZ and FAO. Retrieved August 8, 2014, from http:// www. feedipedia.org/node/224

Heuzé V, Tran G, Bastianelli D, Hassoun P and Lebas F 2013. Cottonseed meal. Feedipedia.org. A programme by INRA, CIRAD, AFZ and FAO. Retrieved August 8, 2014, from http://www.feedipedia.org/node/550

Hidalgo MA, Davis AJ, Dale NM and Dozier III WA 2004. Use of whole pearl millet in broiler diets. Journal of Applied Poultry Research 13, 229-234.

INSEE 2015. Institut National de la Statistique et des Etudes Economiques, INSEE database. Retrieved January 25, 2015, from http://www.bdm.insee.fr/bdm2/ choixCriteres? codeGroupe $=298$

Jacob JP, Mitaru BN, Mbugua PN and Blair R 1996. The effect of substituting Kenyan serena sorghum for maize in broiler starter diets with different dietary crude protein and methionine levels. Animal Feed Science Technology 61, 27-39.
Jacobs C and Parsons CM 2013. The effects of coarse ground corn, whole sorghum, and a prebiotic on growth performance, nutrient digestibility, and cecal microbial populations in broilers fed diets with and without corn distillers dried grains with solubles. Poultry Science 92, 2347-2357.

Khalid MF, Alam MZ, Ahmad F and Mahmood S 2000. Use of cotton seed meal in broiler rations formulated on the basis of total versus digestible amino acids starter phase. International Journal of Agriculture and Biology 2, 346-347.

Kwari ID, Diarra SS, Saleh B, Bovoa PR, Ramat OA and Tochukwu D 2011. Growth, hematology and serology of broiler chickens fed different cultivars of sorghum as replacement for maize in the semi-arid zone of Nigeria. International Journal of Poultry Science 10, 608-612.

Mahmood S, Khan MA, Sarwar M and Nisa M 2006. Chemical treatments to reduce antinutritional factors in salseed (Shorea robusta) meal: effect on nutrient digestibility in colostomized hens and intact broilers. Poultry Science 85, 2207-2215.

Mahmood S, Ali H, Ahmad F and Iqbal Z 2014. Estimation of tannins in different sorghum varieties and their effects on nutrient digestibility and absorption of some minerals in caged white leghorn layers. International Journal of Agriculture and Biology 16, 217-221.

Manwar SJ and Mandal AB 2009. Effect of high moisture storage of pearl millet (Pennisetum typhoides) with or without feed enzymes on growth and nutrient utilization in broiler chickens. Animal Science Journal 80, 438-445.

Nagalakshmi D, Rama Rao SV, Panda AK and Sastry VRB 2007. Cottonseed meal in poultry diets: a review. The Journal of Poultry Science 44, 119-134.

Nir I, Melcion JP and Picard M 1990. Effect of particle size of sorghum grains on feed intake and performance of young broilers. Poultry Science 69, 2177-2184. NRC 1994. Nutrient requirements of poultry. National Academic Press, Washington, DC, USA.

Ojewola GS, Ukachukwu SN and Okulonye EI 2006. Cottonseed meal as substitute for soyabean meal in broiler ration. International Journal of Poultry Science 5, 360-364.

Panigrahi S and Morris TR 1991. Effects of dietary cottonseed meal and irontreated cottonseed meal in different laying hen genotypes. British Poultry Science 32, 167-184.

Pérez-Bonilla A, Novoa S, García J, Mohiti-Asli M, Frikha M and Mateos GG 2012. Effects of energy concentration of the diet on productive performance and egg quality of brown egg-laying hens differing in initial body weight. Poultry Science 91, 3156-3166.

Rae A and Ngaya R 2010. Trends in consumption, production, and trade in livestock and livestock products. In Livestock in a changing landscape: drivers, consequences and responses vol. 1, (ed. H Steinfeld, HA Mooney, F Schneider and LE Neville), pp. 11-33. Island Press, Washington, DC, USA.

Ravindran V 2013a. Main ingredients used in poultry feed formulations. In Poultry development review (ed.) FAO pp. 67-69. FAO, Retrieved August 8, 2014, from www.fao.org/publications.

Ravindran V 2013b. Alternative feedstuffs for use in poultry feed formulations. In Poultry development review (ed.) FAO pp 72-75. FAO, Retrieved August 8, 2014, from www.fao.org/publications.

R Core Team 2013. R: a language and environment for statistical computing. R Foundation for Statistical Computing, Vienna, Austria.

Sauvant D, Schmidely P, Daudin JJ and St-Pierre NR 2008. Meta-analyses of experimental data in animal nutrition. Animal 2, 1203-1214.

Selle PH, Cadogan DJ, Li X and Bryden WL 2010. Review: implications of sorghum in broiler chicken nutrition. Animal Feed Science and Technology 156, 57-74.

St-Pierre NR 2001. Invited review: integrating quantitative findings from multiple studies using mixed model methodology. Journal of Dairy Science 84, 741-755.

Syafwan SG, Wermink JD, Kwakkel RP and Verstegen MWA 2012. Dietary selfselection by broilers at normal and high temperature changes feed intake behavior, nutrient intake, and performance. Poultry Science 91, 537-549.

Torres KAA, Pizauro JM Jr, Soares CP, Silva TGA, Nogueira WCL, Campos DMB, Furlan RL and Macari M 2013. Effects of corn replacement by sorghum in broiler diets on performance and intestinal mucosa integrity. Poultry Science 92, 1564-1571.

Watkins SE, Skinner JT, Adams MH and Waldroup PW 1993. An evaluation of lowgossypol cottonseed meal in diets for broiler chickens 1. Effect of cottonseed meal level and lysine supplementation. Journal of Applied Poultry Research 2, 221-226. Yin YL, Gurung NK, Jeaurond EA, Sharpe PH and de Lange CFM 2002. Digestible energy and amino acid contents in Canadian varieties of sorghum, pearl millet, high-oil corn, high-oil-high-protein corn and regular corn samples for growing pigs. Canadian Journal of Animal Science 82, 385-391. 